\title{
Ege Denizi'nde makine öğrenimi yöntemleri ile anlık deniz seviyesi değişimlerinin tahmini
}

\author{
Ahmet Yavuzdoğan ${ }^{*}$ (D), Emine Tanır KayıkçıiD \\ ${ }^{1}$ Gümüşhane Üniversitesi, Mühendislik ve Doğa Bilimleri Fakültesi, Harita Mühendisliği Bölümü, Gümüşhane, Türkiye. \\ 2Karadeniz Teknik Üniversitesi, Mühendislik Fakültesi, Harita Mühendisliği Bölümü, Trabzon, Türkiye.
}

Öz: Anlı deniz seviyesinin tahmini, jeodezik düşey datumun belirlenmesi ve güncellenmesi, kıyı alanlarının korunmasl, kıyı ekosistemlerinin izlenmesi, kıyı yapılarının planlanması ve bakımı, iklim değişikliği etkilerinin gözlenmesi açısından büyük önem taşımaktadır. Anlık deniz seviyesi tahmini için kullanılan geleneksel yöntemler genellikle doğrusal varsayımlara dayanmaktadır. Ancak deniz seviyesini etkileyen faktörler çok çeşitlidir ve etkileri bölgeden bölgeye değişmektedir. Genellikle doğrusal olmayan ve karmaşık bağımlılık yapılarına sahiptirler. Bu nedenle, doğrusal olmayan deniz seviyeleri doğrusal modeller kullanılarak yüksek duyarlıkta belirlenemez. Makine öğrenimi tahmin yöntemleri ise, son zamanlarda değişkenler arasındaki karmaşık bă̆ımlılık yapılarının modellenmesinde sıklıkla kullanılmaktadır. Bu çalışma kapsamında, anlık deniz seviyesini yüksek doğrulukta tahmin etmek ve doğrusal tahmin yöntemleri ile doğrusal olmayan tahmin yöntemlerini karşılaştırmak amacıyla makine öğrenimi tahmin yöntemlerinden Çoklu Doğrusal Regresyon (ÇDR) doğrusal modeli, Destek Vektör Regresyonu (DVR) doğrusal olmayan model ve Rastgele Orman Regresyonu (ROR) doğrusal olmayan model algoritmaları kullanılmış ve tahmin performansları karşılaştırılmıştır. Çalışma sonucunda anlık deniz seviyesi için en yüksek tahmin performansı ROR ile elde edilmiş olup, en düşük tahmin performansı ise ÇDR yöntemi ile elde edilmiştir. Sonuç olarak anlık deniz seviyelerinin çallşmada kullanılan öncül bilgiler ile ROR kullanılarak yüksek hassasiyette tahmin edilebileceği ve doğrusal tahmin modelinin anlık deniz seviyesinin karmaşık bağımlılık yapısının modellenmesinde yetersiz olduğu gösterilmiştir.

Anahtar Sözcükler: Deniz seviyesi, Makine öğrenimi, Ege Denizi, Çoklu doğrusal regresyon, Destek vektör, Rastgele orman

\section{Forecasting instantaneous sea level changes with machine learning methods in Aegean Sea}

\begin{abstract}
Forecasting instantaneous sea-level is of great importance in terms of determination of geodetic vertical datum and updating, conservation of coastal areas, monitoring coastal ecosystems, maintenance, and planning of coastal structures, monitoring of climate change effects. Traditional methods used for instantaneous sea level estimation are often based on linear assumptions. However, contributors to sea levels are very various and their effects vary from region to region. Generally, they have complex and nonlinear dependence structures. Therefore, nonlinear sea-level cannot be determined with high precision using linear models. Recently, machine learning prediction methods have been frequently used in the modelling of complex dependency structures between variables. Within the scope of this study, to predict the instantaneous sea level with high accuracy and to compare linear estimation methods with nonlinear estimation methods, the Multiple Linear Regression (MLR) linear model, Support Vector Regression (SVR) non-linear model, and Random Forest Regression (RFR) non-linear model algorithms were used, and their prediction performances were compared. As a result of the study, the highest prediction performance for instantaneous sea level was obtained with RFR, and the lowest prediction performance was obtained with the MLR method. As a result, it has been shown that instantaneous sea level can be predicted with high precision using RFR with the features used in this study, and the linear prediction models are insufficient in modelling the complex dependency structure of instantaneous sea level.
\end{abstract}

Keywords: Sea level, Machine learning, Aegean Sea, Multiple linear regression, Support vector, Random forest 


\section{Giriş}

Geleceğe yönelik deniz seviyelerinin yüksek doğrulukta tahmin edilmesi Türkiye gibi üç tarafı denizler ile çevrili bir ülke için kıyı alanlarının korunması, kıyı ekosistemlerinin izlenmesi, kıyı yapılarının bakımı ve planlanması, küresel ısınmanın etkilerinin gözlenmesi ve düşey kontrol ağlarının datumunun belirlenmesi açısından son derece önemlidir. Ayrıca deniz seviyesinin yüksek doğrulukta tahmin edilmesi geleceğe yönelik oluşturulacak etkin su ve kıyı politikalarının hazırlanması açısından da büyük önem taşımaktadır. Deniz seviyesi tahmini için kullanılan geleneksel yöntemler genellikle doğrusal varsayımlara dayanmaktadır. Deniz seviyesi değişimini etkileyen sıcaklık, akış, su tuzluluğu, buharlaşma, yağış gibi hem coğrafi hem de meteorolojik birçok değişken ise doğrusal olmayan bir yapıya sahiptir (Imani, You, \& Kuo, 2014a). Üstelik bu etkiler bölgeden bölgeye değişebilen ve oldukça karmaşık bağımlılık yapılarına sahiptir. Bu nedenle, doğrusal olmayan deniz seviyesi zaman serileri doğrusal modeller kullanılarak doğru şekilde temsil edilemez. Üstelik birçok değişkene bağlı olarak değişen deniz seviyesinin yüksek doğrulukta kestirimi zorlaşmaktadır (Talebizadeh \& Moridnejad, 2011).

Geçmişte deniz seviyesi tahmini için birçok çalışma yapılmıştır. Irvine ve Eberhardt (1992), deniz seviyesini tahmin etmek için aylık ortalamalı deniz seviyesi verilerini kullanarak Erie Gölü ve Ontario Gölü için otoregresif bütünleşik hareketli ortalama (Autoregressive Integrated Moving Average, ARIMA) modellerini geliştirdi. Brundrit (1995), 8 mareograf istasyonunda deniz seviyesini modellemek için ARIMA modellerini kullandı. Vaziri (1997), 12 aylık Hazar Denizi seviyesini tahmin etmek için ARIMA ve Yapay Sinir Ağları (YSA) modellerini kullandı. Meshkani ve Meshkani (1997) Hazar Denizi'ndeki stokastik deniz seviyesindeki dalgalanmaları modellemek için ARIMA modellerini kullandı. Şen, Kadığlu ve Batur (2000) göl seviyesi kayıtlarındaki deterministik kısmı modellemek için basit doğrusal ve periyodik doğrusal olmayan modeller kullanmıştır. Söz konusu çalışmada kullanılan doğrusal model, basit bir doğrusal regresyondur. Göl seviyesi kayıtlarının doğrusal olmayan modellemesi için ikinci dereceden bir Markov modeli ve Fourier serisi kullanılmıştır. Srivastava vd. (2016), üstel yumuşatma durum-uzay modelleri (Exponential smooting state-space, ESM) ve ARIMA modelini kullanarak, deniz seviyesindeki yükselme için nicel tahmin yöntemlerinin birleşik kullanımını araştırmışlardır. Fu, Zhou, Sun ve Tang (2019), deneysel mod ayrıştırma, tekil spektrum analizi ve uydudan türetilen deniz seviyesi anomali tahmini için en küçük kareleri birleştiren bir hibrit model uygulamıştır. Ancak ARIMA veya Box-Jenkins gibi bazı geleneksel yöntemler (Box, Jenkins, Reinsel, \& Ljung, 2015), bir zaman serisinin doğrudan doğrusal bir süreçten üretildiğini varsaydığından, doğrusal olmayan deniz seviyesi zaman serilerini iyi modelleyemeyebilir (Imani, You, \& Kuo, 2014b).

YSA, Destek Vektör Makineleri (DVM), Karar Ağacı teknikleri ve bulanık mantık gibi yapay zekâ (Artificial Intelligence, AI) teknikleri; hidroloji ve su kaynakları mühendisliğinde doğrusal olmayan karmaşık olayları modellemek için sıklıkla kullanılmaktadır (Huang, Peng, Zhang, \& Zhang, 2006; Kisi, Shiri, \& Nikoofar, 2012; More \& Deo, 2003; Wu \& Chau, 2010). Son zamanlarda özellikle DVM'ler ve Rastgele Orman (Random Forest, RO) gibi bazı doğrusal olmayan makine öğrenimi yöntemleri de zaman serilerinin tahmininde sıklıkla kullanılmaktadır (Ghorbani, Khatibi, Aytek, Makarynskyy, \& Shiri, 2010; Güven \& Günal, 2008; Kim, 2003; Rajasekaran, Gayathri, \& Lee, 2008; Yu, Chen, \& Chang., 2006).

Ayrıca makine öğrenimi yöntemleri birçok kez anlık deniz seviyelerini modellemek amacıyla kullanılmıştır. Imani vd. (2014a) yaptığı çalışmada Hazar Denizi’nde DVM kullanarak anlık deniz seviyesini 35 mm karesel ortalama hata (Root Mean Square Error, RMSE) ile belirlemiştir. Ertuğrul ve Tağluk (2017) tarafından yapılan çalışmada ise ortalama deniz seviyeleri Genelleştirilmiş Davranışsal Öğrenme Metodu (Generalized Behavioral Learning Method, GBLM) yöntemi ile tahmin edilmiştir. Bu çalışmada GBLM ile ortalama deniz seviyeleri $69.152 \mathrm{~mm}$ ortalama hata ile belirlenmiştir. Imani, Kao, Lan ve Kuo (2018) yaptı̆̆ı çalışmada Taivan Chiayi kıyılarında anlık deniz seviyesini belirlemek için radyal temelli fonksiyon (Radial Basis Function, RTF), özel bir vektör makinesi yöntemi olan RVM (Relevance Vector Machine), Aşırı 
Öğrenme Makinesi (Extreme Learning Machine, ELM) ve DVM yöntemlerini kullanmıştır. En iyi performansı 34 mm RMSE ile RVM algoritması göstermiştir. Roshni, Samui ve Drisya (2019) de çalışmalarında anlık deniz seviyelerini tahmin etmek için 3 farklı makine öğrenimi algoritması kullanmıştır. Bu algoritmalar RVM, ELM ve Gauss Süreç Regresyonu (Gaussian Process Regression, GPR) algoritmalarıdır. Anlık deniz seviyesini tahmin edebilmek amacıyla meteorolojik değişkenlerden faydalanmışlardır. En iyi tahmin performansı 75 mm RMSE ve 0.96 korelasyon katsayısı ile GPR algoritması ile elde edilmiştir. Anlık deniz seviyesinin tahmini için birçok çalışmada YSA’lar da kullanılmıştır (Imani, You, \& Chung-Yen, 2013; Imani vd., 2014b; Makarynskyy, Makarynska, Kuhn, \& Featherstone, 2004; Zhao, Fan, \& Mu, 2019).

Bu çalışma kapsamında anlık deniz seviyesini yüksek hassasiyetle tahmin edebilmek amacıyla 3 makine öğrenimi algoritması uygulanmış ve tahmin performansları karşılaştırılmıştır. Çalışma kapsamında kullanılan yöntemlerden Çoklu Doğrusal Regresyon (Multiple Linear Regression, ÇDR) algoritması ile anlık deniz seviyesi doğrusal bir model ile tahmin edilmiştir. Böylece doğrusal bir model ile karmaşık bağımlılık yapısına sahip anlık deniz seviyesi değişimlerinin ne kadar hassasiyetle tahmin edileceği gösterilmiştir. Deniz seviyesi tahmini için kullanılan bir diğer fonksiyon olan Destek Vektör Regresyonu (Support Vector Regression, DVR) algoritması ile radyal temelli fonksiyon içeren bir çekirdek fonksiyonu kullanılarak, doğrusal olmayan bir model ile anlık deniz seviyeleri modellenmiştir. Son olarak kullanılan RO Regresyonu (ROR) algoritması ile ağaç algoritma yapısındaki bir fonksiyon ile doğrusal olmayan bir model kullanılarak anlık deniz seviyesi tahmin etmek amaçlanmıştır. Ağaç algoritma yapısı ile çok karmaşık bağımlılıklar modellenebilmekte ve doğrusal olmayan ilişkiler açığa çıkarılabilmektedir.

\section{2. Çalışma Alanı ve Kullanılan Veriler}

$\mathrm{Bu}$ çalışma kapsamında kullanılan iki mareograf istasyonuna (Menteş ve Bodrum) ait deniz seviyesi, hava sıcaklı̆̆ı, hava nemi, hava basıncı, rüzgâr hızı ve rüzgâr yönü verileri Türkiye Ulusal Deniz Seviyesi İzleme Sistemi (TUDES) kapsamında Harita Genel Müdürlüğü tarafindan sağlanan internet adresinden elde edilmiştir (URL-1) (Şekil 1). Ege Denizi’nde bulunan Menteş ve Bodrum istasyonlarından elde edilen ham veriler saatlik alınmış olup, Menteş istasyonu için veriler 1999 - 2014 aralığını, Bodrum istasyonu için ise 1999 - 2010 aralığını kapsamaktadır.

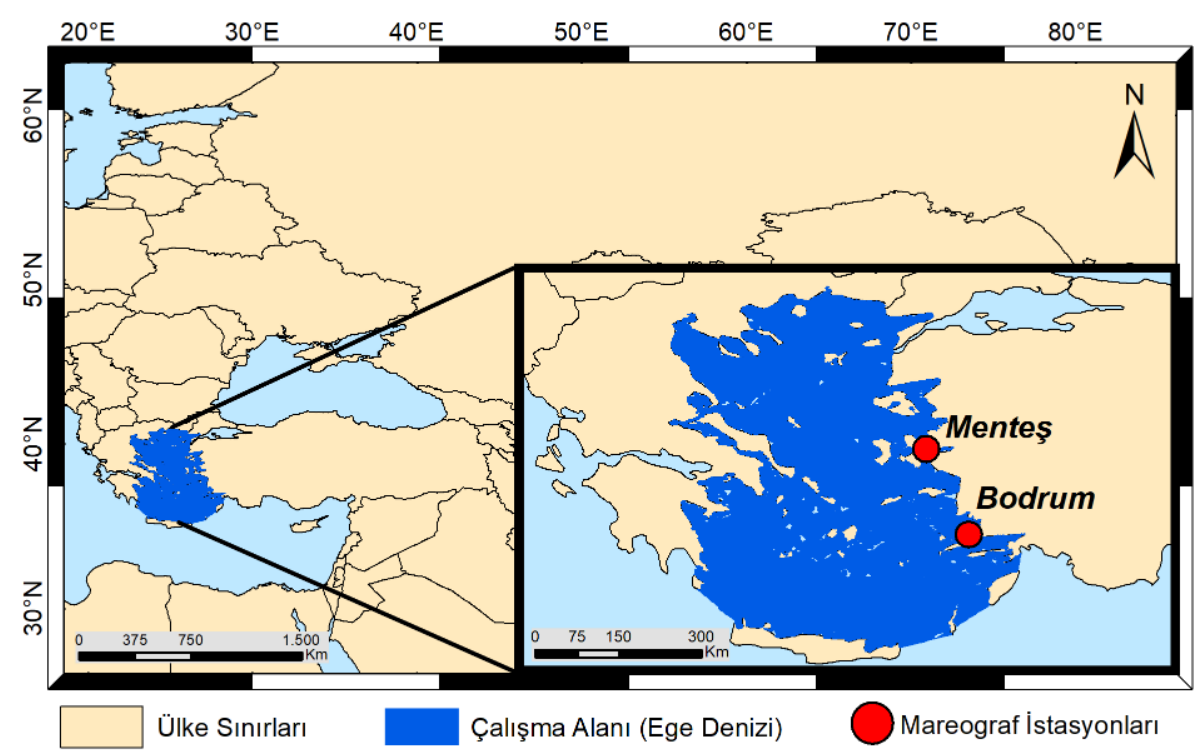

Şekil 1: Çalışma alanı ve mareograf istasyonları 


\section{Yöntem}

\subsection{Veri Önişleme İşlemleri}

Mareograf istasyonlarında kaydedilen anlık deniz seviyesi ölçümlerinin çeşitli analiz algoritmalarında kullanılması için uyuşumsuz ölçü testlerinin yapılması gerekmektedir. Zaman serilerindeki uyuşumsuz ölçüler genellikle zaman serisinin diğer değerleri ile belirgin derecede farklılık gösterirler. Bu nedenle ilk önişleme adımı olarak deniz seviyesi zaman serilerindeki uyuşumsuz ölçülerin tespit edilerek ölçü kümesinden çıkarılması gerekmektedir. Ancak zaman serilerinde uyuşumsuz ölçü testi; trend, mevsimsel, dönemsel bileşen etkisi giderilmiş rastgele bileşene uygulanır. Bu çalışma kapsamında Bölüm 3.2.'de anlatıldığ şsekilde deniz seviyesi zaman serilerinde trend bileşeni, basit doğrusal regresyon modeli ile mevsimsel değişimler ve dönemsel değişimler harmonik analiz yöntemiyle belirlenmiştir. Ardından trend, mevsimsel ve dönemsel bileşenden arındırılmış rastgele bileşene uyuşumsuz ölçü testi uygulanmıştır. Zaman serilerindeki uyuşumsuz ölçülerin tespit edilmesi için literatürde en sık kullanılan yöntemlerden biri k-sigma kuralıdır. Yöntemle, zaman serisinde rastgele bileşene ait ölçünün düzeltmesi, birim ağırlıklı ölçünün ortalama hatasının k katını aşıyor ise, o ölçü uyuşumsuz ölçü olarak ele alınır. Uyuşumsuz ölçü testinde k sınır değeri olarak $\alpha$ yanılma olasılıklarına karşılık gelen ve normal dağıılım tablosundan alınan 1.645, 2.58 ve 3.29 değerleri kullanılır. Genellikle k sınır değeri 3 olarak uygulanır. Bu durumda yöntem 3-sigma yöntemi olarak da anılır.

Bu çalışma kapsamında, mareograf istasyonlarından elde edilen anlık deniz seviyesi zaman serilerindeki uyuşumsuz ölçüler 3-sigma yöntemiyle tespit edilerek ölçü kümesinden çıkarılmıştır. Ardından deniz seviyesi zaman serilerindeki veri alınamayan zamanlara ait veri boşlukları hareketli medyan (moving median) yöntemine göre enterpolasyon ile tamamlanmıştır. Hareketli medyan yöntemi lineer enterpolasyon yöntemlerine göre zaman serisindeki doğrusal olmayan bağımlılıkları koruması nedeniyle tercih edilmektedir. Bu çalışmada ise deniz seviyesi zaman serilerindeki doğrusal olmayan bağımlılıkların korunması ve öğrenme algoritmalarının doğrusal olmayan ilişkileri de öğrenebilmeleri amacıyla veri boşlukları hareketli medyan yöntemi ile enterpolasyon yapılarak doldurulmuştur.

Çalışmada, bağımlı ve bağımsız değişkenlere ait veriler herhangi bir işlemde kullanılmadan önce ağılık merkezine ötelenmiş ve normlandırılmıştır. Bu sayede matrislerde oluşabilecek kondisyon bozuklukları giderilmiştir. $X_{i}$ bağımsız değişkenleri ve $Y_{i}$ bağımlı değişkenleri için $X_{i}{ }^{\prime}$ ve $Y_{i}^{\prime}$ ötelenmiş değerleri, $n$ veri sayısını göstermek üzere;

$X_{i_{\text {ort }}}=\frac{\left[X_{i}\right]}{n} \quad Y_{i_{\text {ort }}}=\frac{\left[Y_{i}\right]}{n}$

$X_{i}^{\prime}=X_{i}-X_{i_{\text {ort }}} \quad Y_{i}^{\prime}=Y_{i}-Y_{i_{\text {ort }}}$

şeklinde elde edilir. $X^{\prime \prime}$ ve $Y^{\prime \prime}$ normlandırılmış değerler;

$$
\begin{array}{ll}
c_{x}=\sqrt{\left[X_{i}^{\prime 2}\right]} & c_{y}=\sqrt{\left[Y_{i}^{\prime 2}\right]} \\
X_{i}^{\prime \prime}=\frac{X_{i}^{\prime}}{c_{x}} & Y_{i}^{\prime \prime}=\frac{Y_{i}^{\prime}}{c_{y}}
\end{array}
$$

formülleri ile hesaplanmıştır. Böylece $X_{i}$ bağımsız değişkenleri ve $Y_{i}$ bağımlı değişkenleri için $X_{i}^{\prime \prime}$ ve $Y_{i}^{\prime \prime}$ ötelenmiş ve normlandırılmış değerleri elde edilmiş ve makine öğrenimi algoritmalarında ötelenmiş ve normlandırılmış değişkenler kullanılmıştır. 


\section{2 Öncül Bilgi (Öznitelik) Çıkarımı}

Uyuşumsuz ölçülerden arındırılmış deniz seviyesi değişim verileri ile anlık deniz seviyelerini tahmin etmek için kullanılacak öncül bilgilerin (öznitelik) elde edilmesi için en küçük kareler doğrusal regresyon ve klasik harmonik analiz yöntemleri kullanılmıştır. Burada;

Doğrusal Model: Anlık deniz seviyesini tahmin etmek için kullanılan çok değişkenli tahmin modeli,

Doğrusal Trend: Anlık deniz seviyesinin uzun zaman içerisinde gösterdiği 1. dereceden olan eğilimi,

Doğrusal Regresyon: Doğrusal trendi ortaya çıkarmak için kullanılan yöntemi,

ifade etmektedir. Deniz seviyesi zaman serilerinin trend bileşeni, basit doğrusal regresyon modeli ile elde edilirken, mareograf istasyonlarındaki gelgit bileşenleri, mevsimsel değişimler ve dönemsel değişimler harmonik analiz yöntemi ile elde edilmiştir. Bu öncül bilgilerin Ege Denizi’ndeki anlık deniz seviyesinin temel bileşen özellikleri hakkında makine öğrenimi algoritmalarına öncül bilgi sağlaması amaçlanmaktadır. Bu nedenle makalenin geri kalanında deniz seviyesi zaman serilerinin trend ve harmonik bileşenleri “deniz seviyesi temel bileşenleri” olarak adlandırılmıştır.

Deniz seviyesini etkileyen önemli etkilerden biri olan rüzgarlar, vektörel bir büyüklük olduğundan, ham veri setinde bulunan rüzgar hızı ve rüzgar yönü değişkenleri ile mareograf istasyonundaki düşey ve yatay yönlerindeki rüzgar bileşenleri Şekil 2'deki gibi çıkarılmıştır.

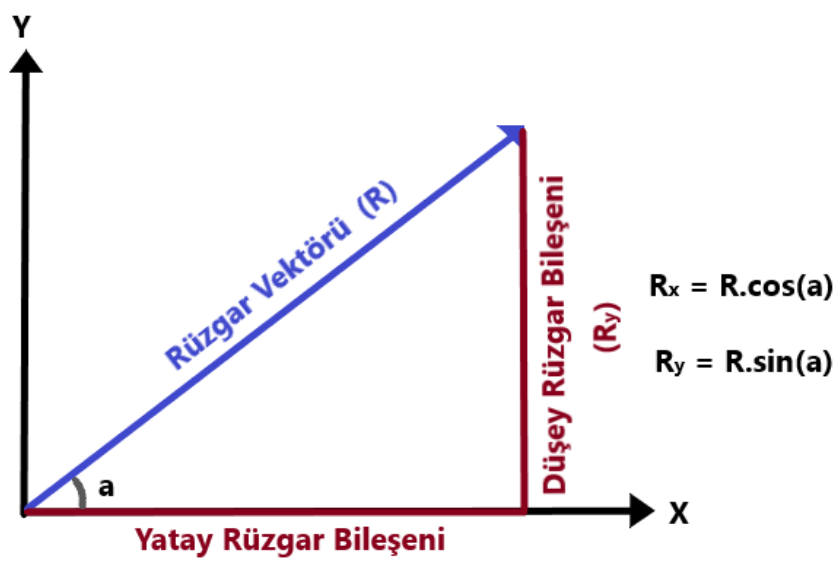

(Rx)

Şekil 2: Yatay ve düşey rüzgar bileşenleri

\subsubsection{Deniz Seviyesi Zaman Serisinin Doğrusal Trendinin Çıkarılması}

Trend, uzun dönemdeki eğilimleri yansıtması bakımından zaman serisinin temel bileşenlerinden biridir. Deniz seviyeleri için ise tarihsel verilerden yola çıkılarak geleceğe yönelik deniz seviyesi değişimi hakkında önemli bilgiler içerir. Bu nedenle Ege Denizi’ndeki genel deniz seviyesi değişimi hakkında makine öğrenimi algoritmalarına bilgi sağlayabilmek amacıyla doğrusal trend, En Küçük Kareler Regresyonu (EKKR) ile elde edilmiştir. EKKR ile doğrusal trend denklemi;

$Y_{i}+v_{i}=a_{0}+a_{1} X_{i}$

şeklinde yazılır. Burada $a_{0}$ katsayısı doğrunun y ekseninde kestiği noktayı ve $a_{1}$ katsayısı ise doğrunun eğimini göstermektedir. $v_{i}$ regresyon modeline ait düzeltme değerini, $X_{i}$ bağımsız değişken, $Y_{i}$ ise bağımlı değişken değerlerini göstermektedir. EKKR'ye göre regresyon katsayılarının hesaplanmasında regresyon modeli için düzeltme denklem sistemi, 
$\mathbf{y}+\mathbf{v}=\mathbf{A x}$

olarak kurulur. Burada A katsayılar matrisi, $\mathbf{x}$ bilinmeyenler vektörü ve $\mathbf{v}$ düzeltme vektörüdür;

$\mathbf{A}=\left[\begin{array}{ll}1 & X_{1} \\ 1 & X_{2} \\ & \vdots \\ 1 & X_{n}\end{array}\right] \quad \mathbf{x}=\left[\begin{array}{l}a_{0} \\ a_{1}\end{array}\right] \quad \mathbf{v}=\left[\begin{array}{c}v_{1} \\ v_{2} \\ \vdots \\ v_{n}\end{array}\right]$

Burada $n$ veri boyutudur. (6) eşitliğindeki düzeltme denklem sisteminin EKK ilkesine göre çözümü sonucunda bilinmeyenler

$\mathbf{x}=\left(\mathbf{A}^{T} \mathbf{A}\right)^{-1} \mathbf{A}^{T} \mathbf{y}$

olarak elde edilir.

\subsubsection{Mevsimsel, Dönemsel ve Gelgit Bileşenlerinin Çıkarılması}

Deniz seviyesi değişimlerinin en önemli nedenlerinden biri gelgitlerdir. Gelgitler deniz seviyeleri üzerinde oldukça düzenli ve harmonik etkilere sahiptir. Bu nedenle deniz seviyesi tahmin çalışmalarında gelgit modelleri sıklıkla kullanılmaktadır. Astronomik gelgit bileşenleri Tablo 1'deki bileşenlerle ifade edilir (Yüksel \& Esin, 2016; Yüksel vd., 2018).

Tablo 1: Astronomik gelgit bileşenleri

\begin{tabular}{ll}
\hline Kaynak & Periyot (saat) \\
\hline Main lunar, yar1-günlük & 12.42 \\
\hline Main solar, yar1-günlük & 12.00 \\
\hline Lunar elliptic, yarı-günlük & 12.66 \\
\hline Lunar-solar, yarı-günlük & 11.97 \\
\hline Lunar solar, günlük & 23.93 \\
\hline Main lunar, günlük & 25.82 \\
\hline Main solar, günlük & 24.07 \\
\hline Lunar fortnightly (15 günlük), uzun periyotlu & 327.86 \\
\hline Lunar monthly (aylik), uzun periyotlu & 661.30 \\
\hline
\end{tabular}

$\mathrm{Bu}$ etkilerin dışında gelgit hareketleri, meteorolojik etkiler, sı̆̆ sularda meydana gelen taban sürtünmeleri gibi birçok farklı faktörle de ilişkilidir. Zaman serilerinde gelgit sinyalleri birçok farklı genlik ve frekansa sahip harmonik sinyallerin toplamı şeklinde ifade edilmektedir. Bu sinyaller yarı-günlük, günlük veya daha uzun periyotlarda olabilir. Bir harmonik model;

$h_{i}=Z_{o}+a t_{i}+\sum_{j=1}^{M} A_{j} \cos \left(\omega_{j} t_{i}-\theta_{j}\right)$

şeklinde ifade edilir (Teferle, 2003). Gelgiti oluşturan her bir bileşene ait genlik ve faz değerleri klasik harmonik analizlerle belirlenir. Bir sinyale ait genlik ve faz açıları (9) eşitliğinde verilen formül genişletilerek elde edilir (Sezen, 2006; Teferle, 2003).

$A_{j} \cos \left(\omega_{j} t_{i}-\theta_{j}\right)=A_{j}\left[\cos \left(\omega_{j} t_{i}\right) \cos \left(\theta_{j}\right)+\sin \left(\omega_{j} t_{i}\right) \sin \left(\theta_{j}\right)\right]$

$A_{j} \cos \left(\theta_{j}\right)=B_{j}$

$A_{j} \sin \left(\theta_{j}\right)=C_{j}$

$\omega_{j}=2 \pi f_{j}$ 
kabulleri yapılarak harmonik analiz denkleminde yerine konulursa;

$h_{i}=Z_{o}+a\left(t_{i}-t_{0}\right)+\sum_{j=1}^{M} B_{j} \cos \left(2 \pi f_{j}\left(t_{i}-t_{0}\right)\right)+C_{j} \sin \left(2 \pi f_{j}\left(t_{i}-t_{0}\right)\right)$

denklemi elde edilir. Bu denkleme göre $t_{0}$ başlangıç epoğunda $\mathbf{A}$ katsayılar matrisi ve $\mathbf{x}$ bilinmeyenler vektörü aşağıdaki gibi yazılır. Her periyodik etkiye karşılık A matrisine 2 sütun eklenir (Sezen, 2006; Teferle, 2003).

$\mathbf{A}=\left[\begin{array}{cccc}1 & t_{1}-t_{0} & \sin \left(2 \pi f_{1}\left(t_{1}-t_{0}\right)\right) & \cos \left(2 \pi f_{1}\left(t_{1}-t_{0}\right)\right) \\ 1 & t_{2}-t_{0} & \sin \left(2 \pi f_{1}\left(t_{2}-t_{0}\right)\right) & \cos \left(2 \pi f_{1}\left(t_{2}-t_{0}\right)\right) \\ \cdot & \cdot & \cdot & \cdot \\ \cdot & \cdot & \cdot & \cdot \\ \cdot & \cdot & \cdot & \cdot \\ 1 & t_{N-1}-t_{0} & \sin \left(2 \pi f_{1}\left(t_{N-1}-t_{0}\right)\right) & \cos \left(2 \pi f_{1}\left(t_{N-1}-t_{0}\right)\right) \\ 1 & t_{N}-t_{0} & \sin \left(2 \pi f_{1}\left(t_{N}-t_{0}\right)\right) & \cos \left(2 \pi f_{1}\left(t_{N}-t_{0}\right)\right)\end{array}\right], \quad \mathbf{x}=\left[\begin{array}{c}Z_{0} \\ a \\ B_{1} \\ C_{1}\end{array}\right]$

EKK yöntemine göre yapılan dengeleme işlemi sonucunda her bir periyodik bileşen için B ve C katsayıları ile genlik ve faz açısı;

$A_{j}=\sqrt{B_{j}^{2}+C_{j}^{2}}$ ve $\theta_{j}=\arctan \frac{C}{B}$

formülleri ile elde edilir. Burada;

$h_{i} \quad: t_{i}$ zamanındaki ortalama deniz seviyesi değeri

$t_{i} \quad$ : başlangıç epoğundan itibaren geçen gün sayısı

a : doğrusal trend

$Z_{0} \quad$ : başlangıç epoğundaki ortalama deniz seviyesi

M : modelde kullanılan anlamlı gelgit bileşenlerinin toplam sayısı

$N \quad$ : aylık toplam ortalama değer sayısı

$A_{j}, \omega_{j}, \theta_{j}: \mathrm{j}$. bileşenin genliği, frekansı ve faz açısıdır.

Klasik harmonik analizle ilgili ayrıntılı bilgiler Pugh (1996) çalışmasından elde edilebilir. Bu çalışma kapsamında klasik harmonik analiz yöntemi ile mareograf istasyonlarında kaydedilen deniz seviyesi zaman serilerinde mevsimsel, dönemsel ve gelgit bileşenleri Pawlowicz, Beardsley ve Lentz (2002) tarafindan geliştirilen, MATLAB tabanlı T_TIDE yazılımı kullanılarak elde edilmiştir. Bu yazılım ile gelgitlere sebep olan en temel 64 farklı bileşene ait sinyallerin faz, genlik ve frekans değerleri hesaplanabilmektedir. Bu nedenle oşinografi ile ilgili çalışmalarda özellikle genlik bileşenlerinin modellenmesi için T_TIDE yazılımı sıklıkla kullanılmaktadır (Arns vd., 2020; Costa vd., 2020; Juva, Flögel, Karstensen, Linke, \& Dullo, 2020). Bu çalışma kapsamında harmonik analiz yöntemi ile belirlenen gelgit bileşenleri, mevsimsel bileşenler ve dönemsel bileşenler "Harmonik Bileşenler" olarak adlandırılmıştır.

\subsection{Deniz Seviyesi Tahmini İçin Makine Öğrenimi Algoritmaları}

Bu çalışmada Ege Denizi’ndeki anlık deniz seviyesi 3 farklı makine öğrenimi algoritması kullanılarak tahmin edilmiştir. Bu yöntemler regresyon temelli algoritmalardır. Regresyon problemlerinde amaç bağımsız değişkenlerden bağımlı değişkene giden yolun bulunmasıdır. Bu yol sadece bir korelasyon katsayısı ile ifade edilemeyecek kadar kompleks bir yapıda olabilir. $\mathrm{Bu}$ nedenle regresyon problemleri için birçok farklı algoritma geliştirilmiştir. Algoritmaların başarısı kullanılan veri yapısına ve değişkenler arasındaki ilişkinin karmaşıklığına göre değişmektedir. İlgili çalışma kapsamında deniz seviyesi tahmini için ÇDR, DVR, ROR algoritmaları kullanılmıştır. 


\subsection{1 Çoklu Doğrusal Regresyon}

ÇDR algoritması temelde birçok bağımsız değişken kullanılarak bir bağımlı değişkeni bulacak çok boyutlu doğru denkleminin elde edilmesi işlemidir. ÇDR algoritması genellikle bağımlı ve bağımsız değişkenler arasında doğrusal bir ilişki varsa doğru sonuçlar verebilmektedir. ÇDR ile değişkenler arasındaki ilişkiyi gösteren doğru denklemi;

$y=a+b_{1^{*}} x_{1}+b_{2} * x_{2}+\cdots \ldots \ldots+b_{n} * x_{n}$

şeklinde yazılır. Burada $y$ bağımlı değişkeni $b_{n}$ ise $\mathrm{n}$. bağımsız değişkeni ifade etmektedir.

\subsubsection{Destek Vektör Regresyonu}

DVR algoritması ise DVM algoritmasına dayalı sınıflandırma algoritmasının tahmin uygulamalarında kullanılmak üzere geliştirilmiş özel bir formudur. Günümüzde birçok sınıflandırma ve regresyon problemlerinde kullanılmakta olan DVM algoritması ilk olarak Cortes ve Vapnik (1995) tarafindan literatüre kazandırılmıştır. Regresyon problemlerinde kullanılan DVR algoritması ise ilk olarak Drucker, Burges, Kaufman, Smola ve Vapnik (1997) çalışması ile sunulmuştur. DVR algoritmasında amaç fonksiyonu, bir marjin aralığına (ع) maksimum sayıda noktayı en küçük hata ile alabilecek doğru veya eğri fonksiyonunun belirlenmesidir (Müller vd., 1997) (Şekil 3).

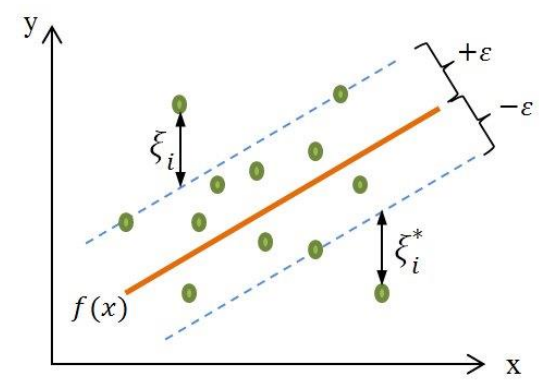

Şekil 3: DVR algoritması (Chanklan vd., 2018)

DVR algoritmasının önemli bir parametresi de çekirdek (kernel) fonksiyonudur. Çekirdek fonksiyonu ile tahmin edilecek regresyon çizgisinin şekli belirlenebilmektedir. Çekirdek fonksiyonunun bir doğru denklemi seçilmesi halinde değişkenler arasındaki doğrusal ilişkiler DVR ile belirlenir. Çekirdek fonksiyonu polinomal bir eğri fonksiyonu olabileceği gibi DVR uygulamalarında sıklıkla kullanılan RTF de olabilir (Şekil 4).

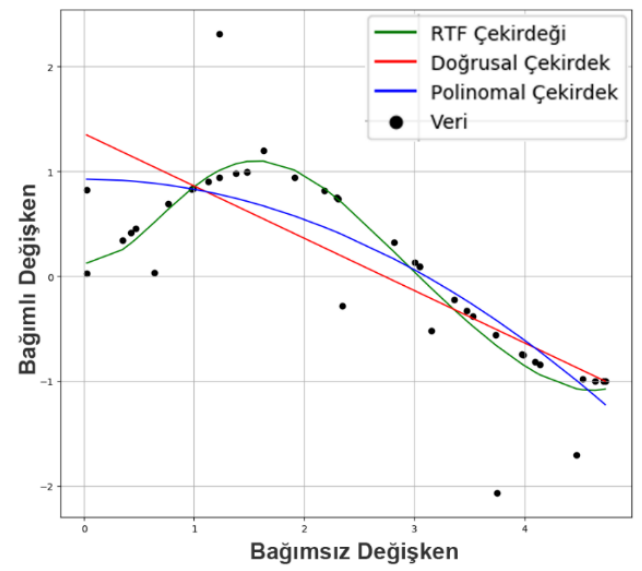

Şekil 4: DVR algoritmasında çekirdek fonksiyonları 


\subsubsection{Rastgele Orman Regresyonu}

ROR algoritması, tahmin uygulamalarında bağımlı değişkeni tahmin etmek için birçok karar ağacı yapısının kullanıldığı bir regresyon yöntemidir. Karar ağaçları ise düğümlerinde karar değişkenlerini, yapraklarında tahmin değerlerini bulunduran bir yapıya sahiptir. Karar ağaçlarında amaç, hata fonksiyonunun değerini minimuma indirgemektir. Hata fonksiyonu bir hata metriği yardımıyla ölçülebilir. Bu çalışmada RO’da bulunan karar ağaçlarının hata fonksiyonları için karesel hataların toplamı (Sum of Squared Errors, SSE) metriği kullanılmıştır. $\bar{X}$, bağımsız $x$ değişkenlerinin ortalamasını göstermek üzere SSE ve Hata Fonksiyonu (HF);

$S S E=\sum_{i=1}^{N}\left(x_{i}-\bar{X}\right)^{2}$

$H F=\frac{M_{\text {sol }}}{M} M S E_{\text {sol }}+\frac{M_{\text {sag }}}{M} M S E_{\text {sag }}$

formülleri ile hesaplanır. Burada $M$ örnek sayısını göstermektedir (Gülaçar, 2018). ROR'da oluşturulan rastgele alt kümeler ile çok sayıda karar ağacının çıktı verilerinin ortalaması alınarak son tahmin değeri belirlenir (Şekil 5).

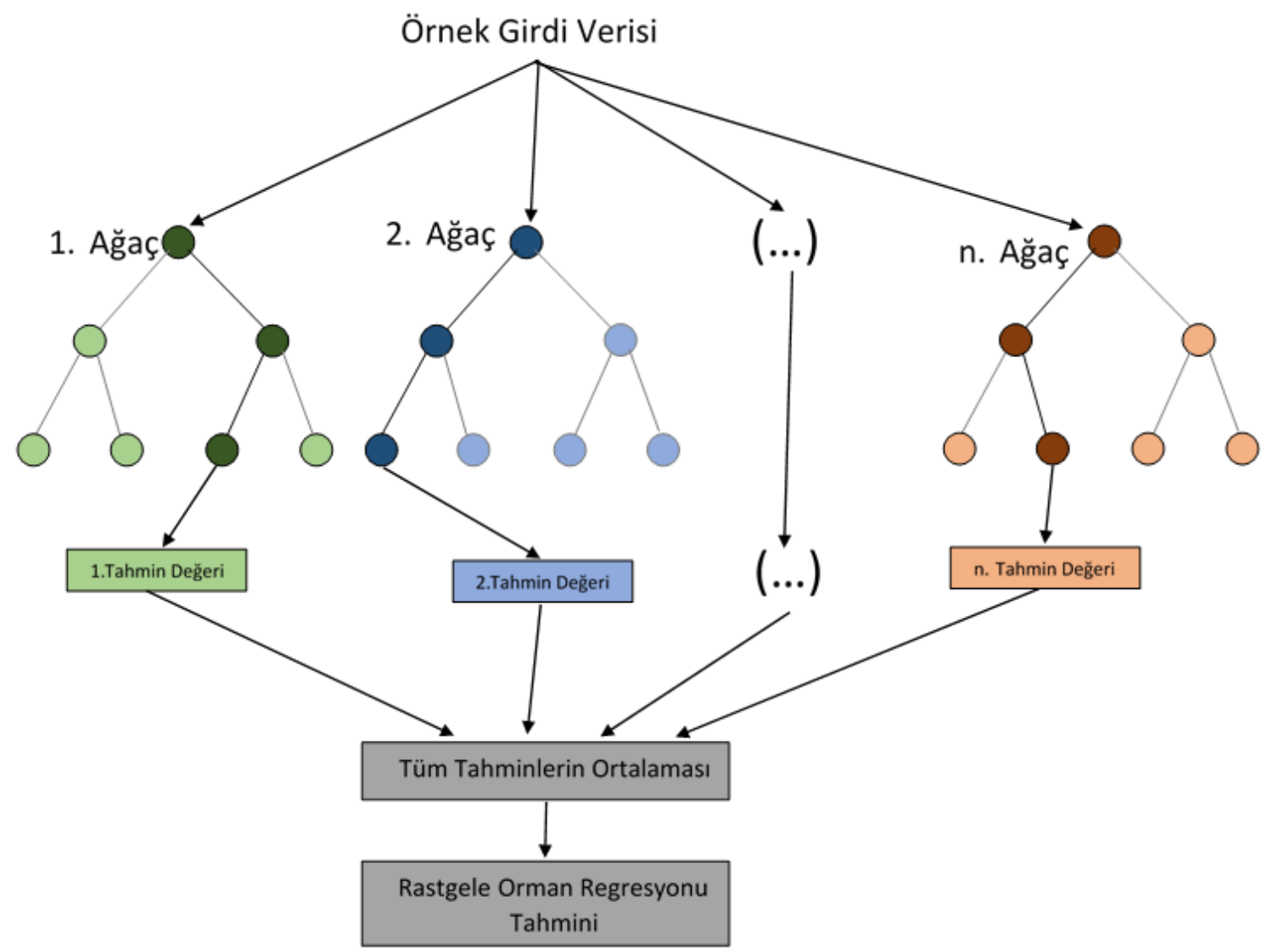

Şekil 5: ROR algoritma yapısı

\subsection{Algoritmaların Performanslarının Karşılaştırılması}

$\mathrm{Bu}$ çalışmada algoritmaların hem eğitim hem de test veri setlerinde model performanslarını karşılaştırmak amacıyla zaman serisi tahmin çalışmalarında sıklıkla kullanılan $r$ (Pearson korelasyon katsayısı) ve $R M S E$ metrikleri kullanılmıştır. $r$ korelasyon katsayısı model verilerinin gerçek veriler ile uyumluluğunun bir ölçümü iken, $R M S E$ gerçek veriler ile model verileri arasındaki farkı gösteren bir metriktir. $r$ ve $R M S E$ metrikleri; 
$r=\frac{\sum_{i=1}^{n}\left(y_{i}-\bar{y}\right)\left(y_{i}^{p}-\bar{y}^{p}\right)}{\sqrt{\sum_{i=1}^{n}\left(y_{i}-\bar{y}\right)^{2} \sum_{i=1}^{n}\left(y_{i}^{p}-\bar{y}^{p}\right)^{2}}}$

$R M S E=\sqrt{\frac{\sum_{i=1}^{n}\left(y_{i}-y_{i}^{p}\right)^{2}}{n}}$

formülleri kullanılarak hesaplanabilir. Burada $y_{i}$ ve $y_{i}^{p}$ sırasıyla i. zamanda gözlemlenen ve tahmin edilen verileri, $n$ veri sayısını, $\bar{y}$ ve $\bar{y}^{p}$ ortalama gözlem ve ortalama tahmin değerlerini göstermektedir.

\section{Sayısal Uygulama}

Bu çalışma kapsamında Ege Denizi’nde bulunan 2 mareograf istasyonundaki anlık deniz seviyesi değişimlerini tahmin etmek amacıyla, meteorolojik değişkenler (hava sıcaklığı, hava basıncı, hava nemi, düşey ve yatay rüzgâr bileşenleri) ve deniz seviyesi temel bileşenleri (doğrusal trend ve harmonik bileşenler) kullanılarak 3 farklı makine öğrenimi algoritması ile tahmin modelleri geliştirilmiş ve uygulanan modellerin performansları karşılaştırılmıştır.

\subsection{Deniz Seviyesi Temel Bileşenlerinin Öncül Tahmini}

Deniz seviyesi temel bileşenleri olan trend ve harmonik bileşenlerinin öncül tahminleri makine öğrenimi algoritmalarında öncül bilgi (öznitelik) olarak kullanılmıştır. Bodrum ve Menteş istasyonları zaman serilerinde trend bileşeninin öncül tahmini için uygulanan basit doğrusal regresyon modelinden elde edilen $a_{1}$ eğim katsayısı için parametre anlamlılık testi uygulanmıştır. $a_{1}$ eğim katsayısı için

$t_{a_{1}}=\frac{\left|a_{1}\right|}{m_{a_{1}}}$

olarak elde edilen test değerleri $\alpha=0.05$ yanılma olasılığı ve $f=n-2$ serbestlik derecesi ile $t$ dağılım tablosundan alınan tablo değeri 1.96 değerleriyle karşılaştırılmıştır (Tablo 2-3).

Tablo 2: Bodrum istasyonu doğrusal trend bileşeni katsayı anlamlılı testi

\begin{tabular}{cccc}
\hline $\boldsymbol{a}_{\mathbf{1}}$ katsayısı & Test değeri & T-Tablo değeri & Sonuç \\
\hline 0.1234 & 38.3583 & 1.96 & $a_{1}$ anlamlı \\
\hline
\end{tabular}

Tablo 3: Menteş istasyonu doğrusal trend bileşeni katsayı anlamlıık testi

\begin{tabular}{cccc}
\hline $\boldsymbol{a}_{\mathbf{1}}$ katsayısı & Test değeri & T-Tablo değeri & Sonuç \\
\hline 0.1461 & 54.1474 & 1.96 & $a_{1}$ anlamlı \\
\hline
\end{tabular}

Basit doğrusal regresyon modeli ile trend bileşeninin öncül tahmini yapılıp trend etkisi giderilmiş deniz seviyesi zaman serileri elde edilmiştir. Daha sonra, harmonik bileşenlerin öncül tahmini için trend etkisi giderilmiş zaman serilerine harmonik analiz uygulanmıştır. İstasyonlardaki bu harmonik bileşenlerin çıkarılması için zaman serisinde bulunabilecek uzun dönemli, yıllık, yarı yıllık, aylık, 15 günlük, günlük ve yarı-günlük ve daha kısa süreli sinyaller incelenmiştir. Yapılan harmonik analiz sonucunda istasyonlardaki saatlik deniz seviyesi zaman serilerinden elde edilen sinyallerin genlik, faz ve frekans değerleri Tablo 4 ve Tablo 5'teki gibidir. 
Tablo 4: Menteş istasyonunda anlamlı sinyallerin frekans, genlik ve faz değerleri

\begin{tabular}{lccccc}
\hline Sinyal adı & Frekans & Genlik & $\begin{array}{c}\text { Genlik } \\
\text { duyarlılığı }\end{array}$ & Faz & $\begin{array}{c}\text { Faz } \\
\text { duyarlılı̆̆ }\end{array}$ \\
\hline$S A$ & 0.000114 & 0.2238 & 0.090 & 147.03 & 25.37 \\
\hline$P 1$ & 0.041553 & 0.0227 & 0.011 & 347.13 & 29.63 \\
\hline$P S I 1$ & 0.041895 & 0.0213 & 0.013 & 105.85 & 30.58 \\
\hline$M 2$ & 0.080511 & 0.0336 & 0.021 & 105.96 & 37.65 \\
\hline$H 2$ & 0.080626 & 0.1434 & 0.022 & 96.71 & 8.82 \\
\hline$T 2$ & 0.083219 & 0.0348 & 0.020 & 286.82 & 36.62 \\
\hline$R 2$ & 0.083333 & 0.0336 & 0.023 & 300.17 & 36.40 \\
\hline $2 M N 6$ & 0.083447 & 0.0391 & 0.023 & 337.69 & 29.18 \\
\hline & 0.240022 & 0.0051 & 0.003 & 60.33 & 37.08 \\
\hline
\end{tabular}

Tablo 5: Bodrum istasyonunda anlamlı sinyallerin frekans, genlik ve faz değerleri

\begin{tabular}{lccccc}
\hline Sinyal adı & Frekans & Genlik & $\begin{array}{c}\text { Genlik } \\
\text { duyarlılı̆̆ }\end{array}$ & Faz & $\begin{array}{c}\text { Faz } \\
\text { duyarlılığı }\end{array}$ \\
\hline$S A$ & 0.000114 & 0.0524 & 0.009 & 109.53 & 9.72 \\
\hline$O 1$ & 0.038731 & 0.0027 & 0.001 & 162.68 & 32.98 \\
\hline$P S I 1$ & 0.041895 & 0.0034 & 0.001 & 230.73 & 22.32 \\
\hline$H 2$ & 0.080626 & 0.0060 & 0.002 & 352.52 & 19.84 \\
\hline$R 2$ & 0.083447 & 0.0061 & 0.002 & 179.95 & 22.85 \\
\hline$M 4$ & 0.161023 & 0.0001 & 0.000 & 203.53 & 44.66 \\
\hline
\end{tabular}

Burada SA bir y1llık periyoda sahip mevsimsel bileşeni, P1 - PSI1 - O1 günlük periyoda sahip günlük gelgit bileşenini, $M 2$ $H 2$ - T2 - S2 - R2 sinyalleri yarım günlük gelgit bileşenlerine ait sinyalleri, M4 6 saatlik gelgit bileşenini ve $2 M N 6$ sinyali ise 4 saatlik gelgit bileşenini göstermektedir. Bodrum istasyonu için bulunan mevsimsel bileşen ve anlamlı gelgit sinyallerinin toplamı olan gelgit bileşeni Şekil 6'da verilmiştir.
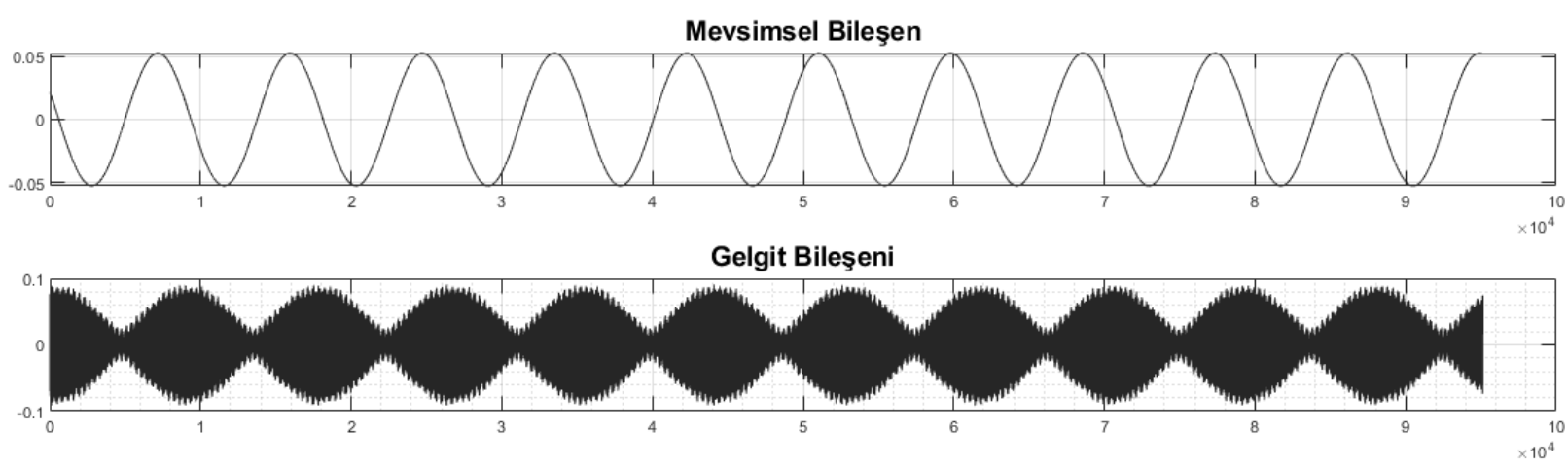

Şekil 6: Bodrum istasyonu için mevsimsel bileşen ve gelgit bileşeni

Öncül bilgiler;

- Tablo 2 ve Tablo 3 'te verilen doğrusal trend bileşenleri,

- Tablo 4, Tablo 5'te verilen ve Şekil 6'da gösterilen harmonik bileşenleri,

- İstasyonlarda kaydedilen meteorolojik bileşenleri (hava sıcaklığı, hava basıncı, hava nemi, x yönündeki rüzgar bileşeni, y yönündeki rüzgar bileşeni)

olarak belirlenmiştir. Bu şekilde trend ve harmonik bileşenlerden oluşan temel öncül bileşenler ve meteorolojik bileşenlerle, 
Bodrum istasyonu için 12 adet, Menteş istasyonu için ise 15 adet farklı öncül bilgi değişkeni kullanılmıştır. İstasyonlardaki öncül bilgi (öznitelik) çıkarımı tamamlandıktan sonra makine öğrenimi algoritmalarının eğitimi ve test edilmesi aşamasına geçilmiştir.

\subsection{Makine Öğrenimi Algoritmalarının Eğitilmesi ve Test Edilmesi}

İstasyon bölgelerine ait deniz seviyesi temel bileşenlerine ait öncül bilgilerin elde edilmesinin ardından ÇDR, DVR ve ROR algoritmaları eğitim verileri kullanılarak eğitilmiştir. Algoritmaların eğitimi için kullanılan öncül bilgiler Şekil 7'de verilmiştir. Öncül bilgi verilerinin \% 70’i makine öğrenimi algoritmalarının eğitimi için eğitim verisi olarak, \%30’u ise tahmin model performanslarını değerlendirmek üzere test verisi olarak rastgele seçilmiştir. Makine öğrenimi algoritmalarının eğitimi ve test edilmesi için Pedregosa vd. (2011) tarafından geliştirilen Python ortamındaki SciKit-Learn kütüphanesi kullanılmıştır.

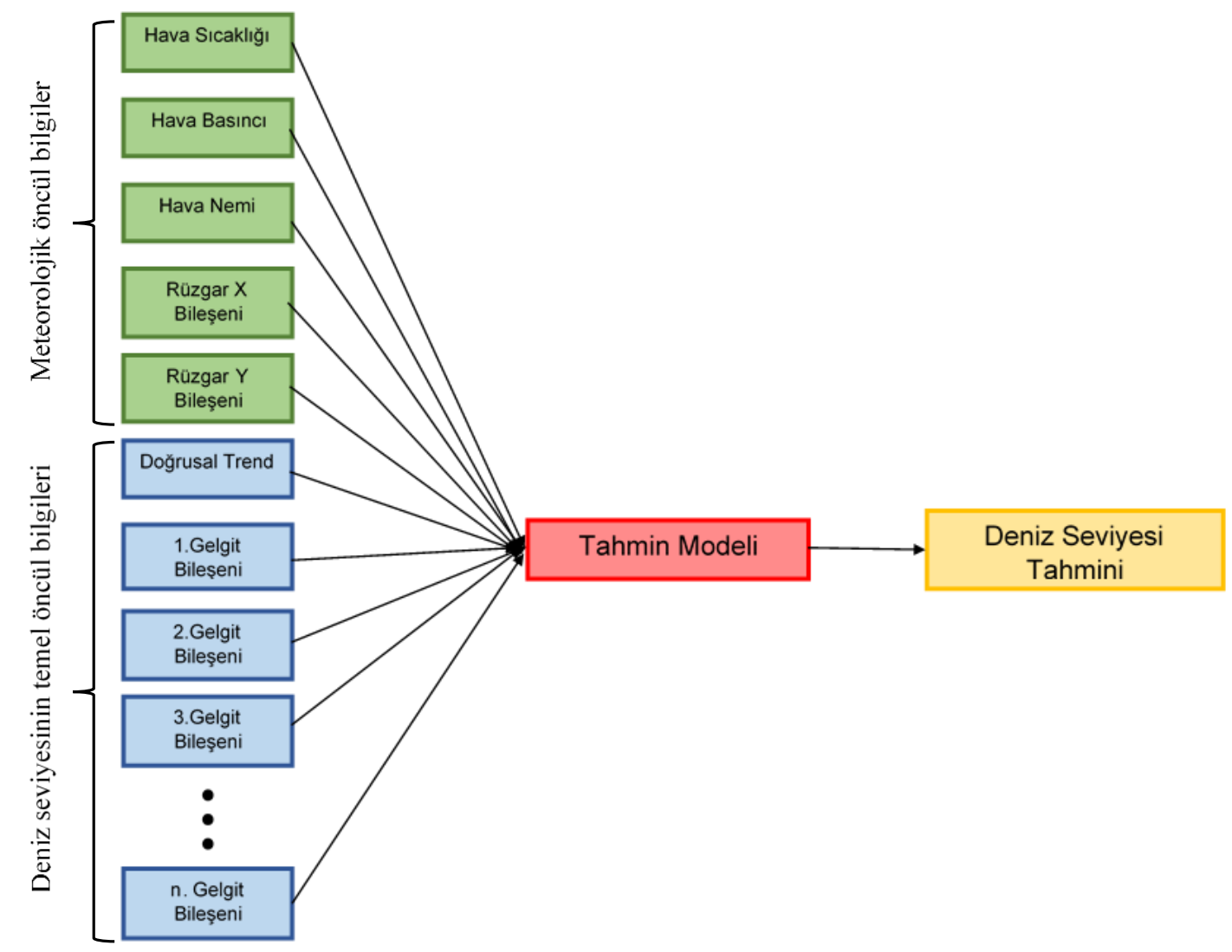

Şekil 7: Eğitim için kullanılan öncül bilgiler

\subsection{1 Çoklu Doğrusal Regresyon Algoritması Eğitim ve Test Performansı}

ÇDR algoritması eğitim ve test verileri kullanılarak eğitilmiştir. Eğitilmiş model kullanılarak eğitim, test ve tüm dönemler için deniz seviyesi tahminleri yapılmıştır. Yapılan tahmin değerleri gerçek değerlerle karşılaştırılarak, modellerin eğitim, test ve tüm veri seti için tahminlerinin doğruluk performansları değerlendirilmişstir (Şekil 8). 

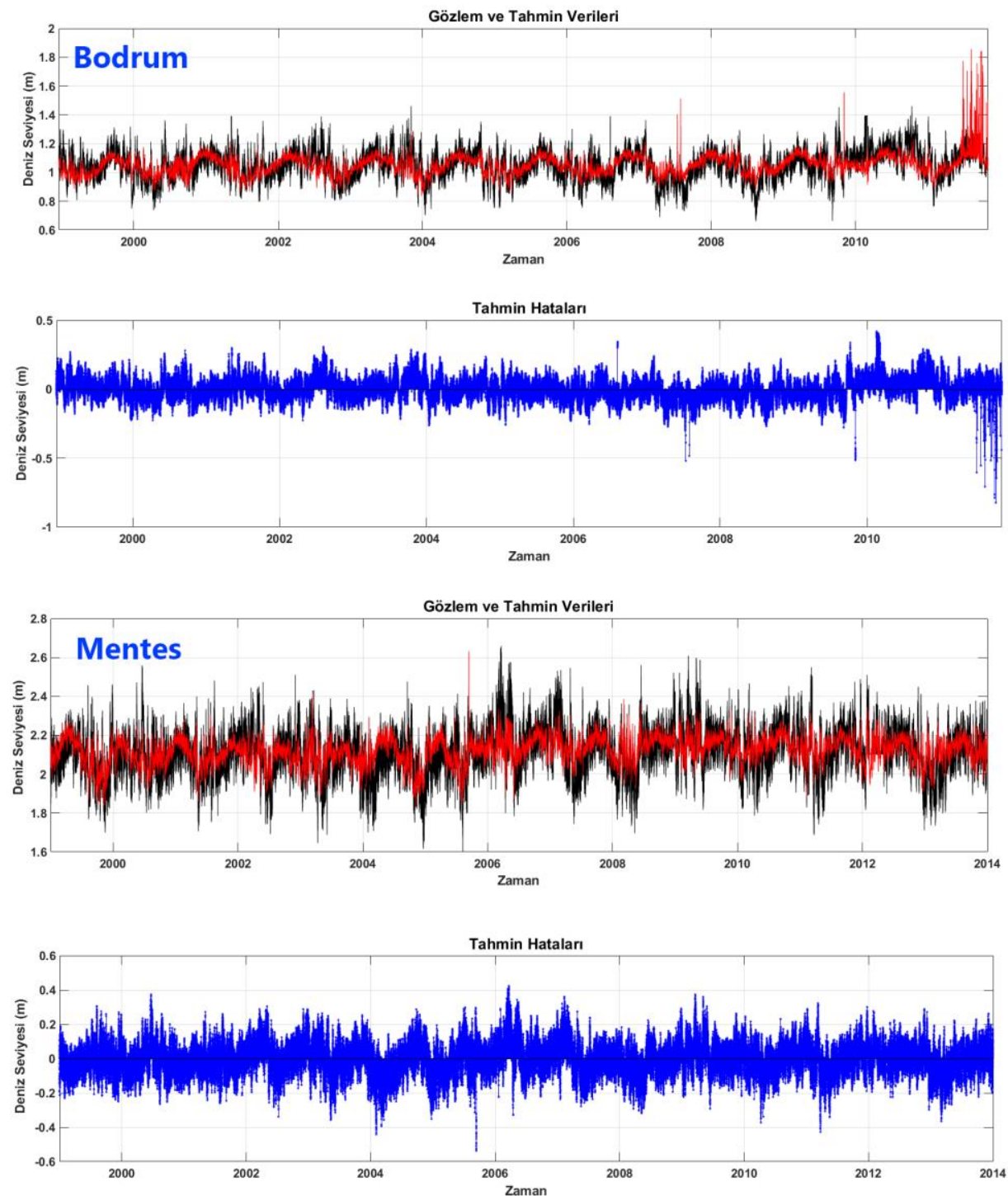

Şekil 8: ÇDR algoritması tahminleri

ÇDR algoritmasının eğitim ve test veri setindeki deniz seviyesi tahmin performansları $r$ Pearson korelasyon katsayısı ve RMSE metrikleri kullanılarak ölçülmüştür. Elde edilen tahmin performansları Şekil 9'da verilmiştir.

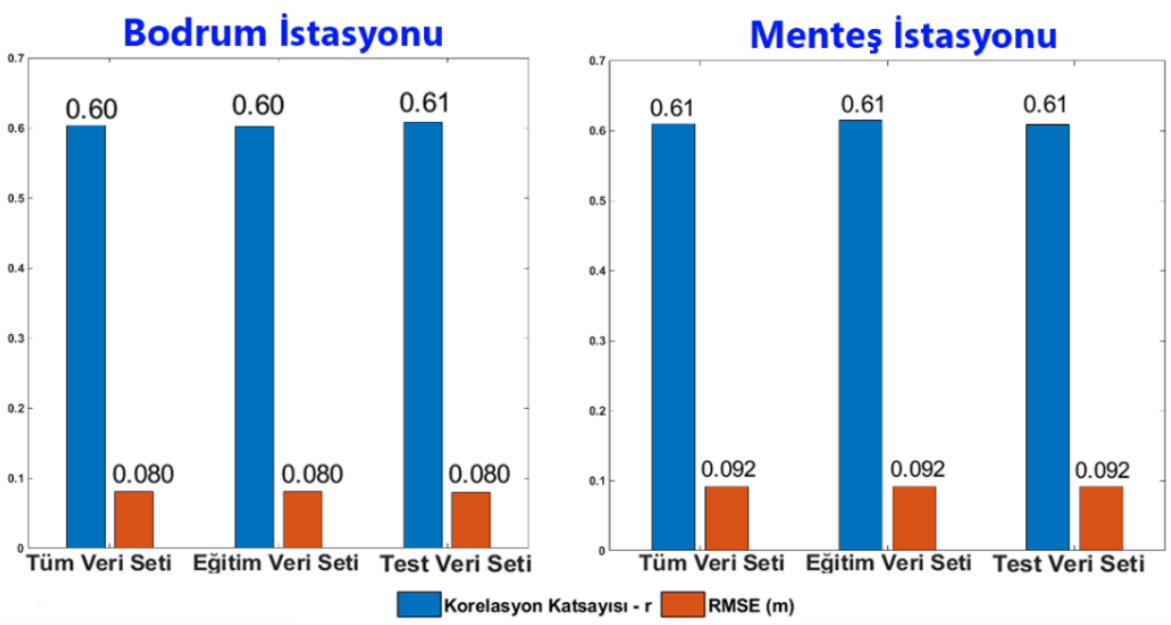

Şekil 9: ÇDR algoritması deniz seviyesi tahmin performansı 
Şekil 8 ve Şekil 9'da görüldüğü gibi ÇDR algoritması hem eğitim hem test döneminde her iki istasyondaki deniz seviyesi tahminlerinde benzer sonuçlar vermektedir. Özellikle Bodrum istasyonunun son dönem tahminleri oldukça yüksek olup, gerçek veriden uzaktır. $\mathrm{Bu}$ durum karmaşık bağımlılık yapılarına sahip veri setlerinde doğrusal fonksiyonlarının tahminlerinin ne kadar yetersiz olduğunu göstermesi bakımından önemlidir.

\subsubsection{Destek Vektör Regresyonu Algoritması Eğitim ve Test Performansı}

RTF çekirdeği kullanılan DVR algoritmasının istasyonlardaki deniz seviyesi tahminleri Şekil 10'da verilmiştir. Ayrıca DVR algoritmasının eğitim ve test veri setindeki deniz seviyesi tahmin performansları $r$ ve RMSE metrikleri cinsinden Şekil 11'de verilmiştir.
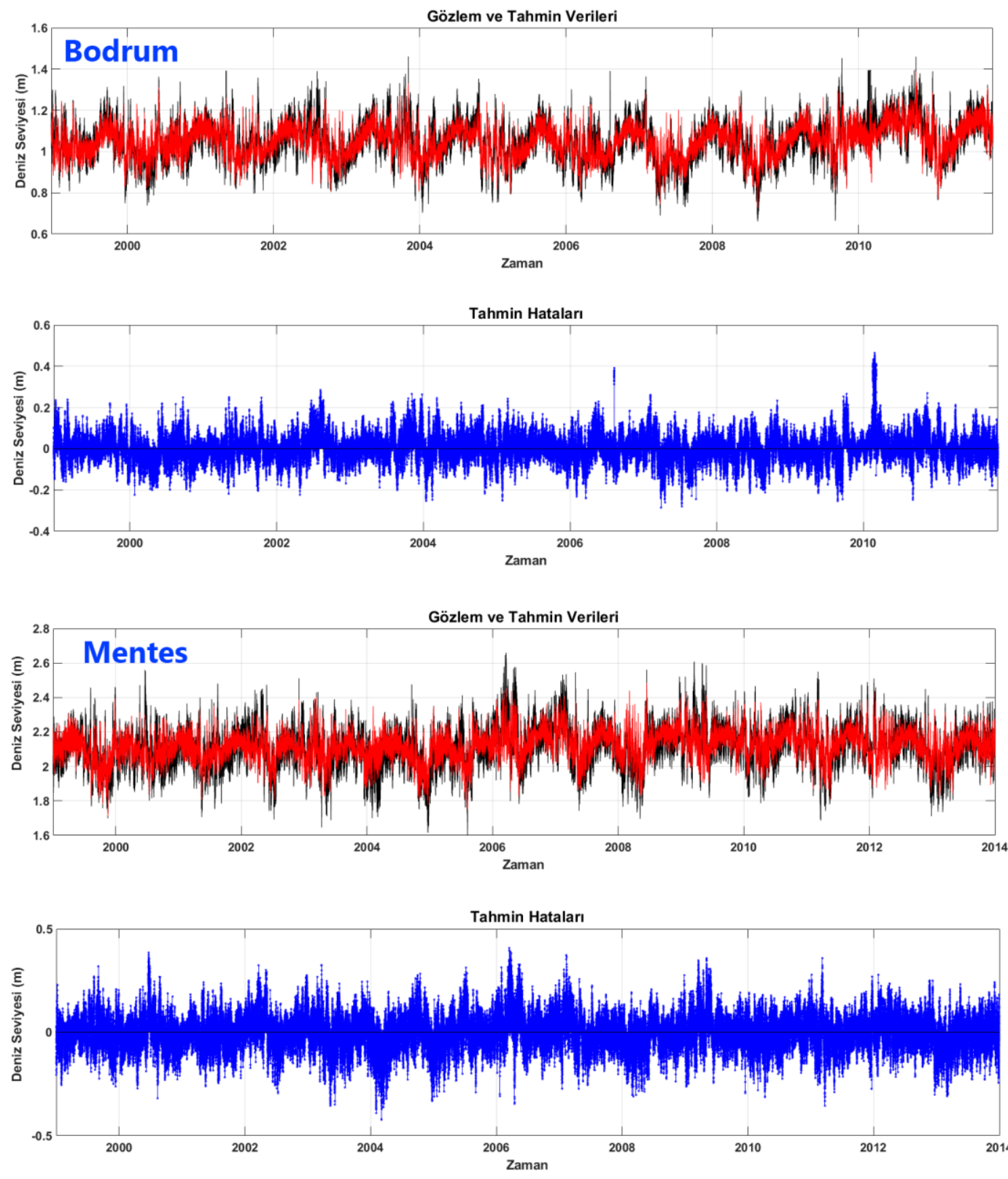

Şekil 10: DVR algoritması tahminleri (tüm veri seti için) 


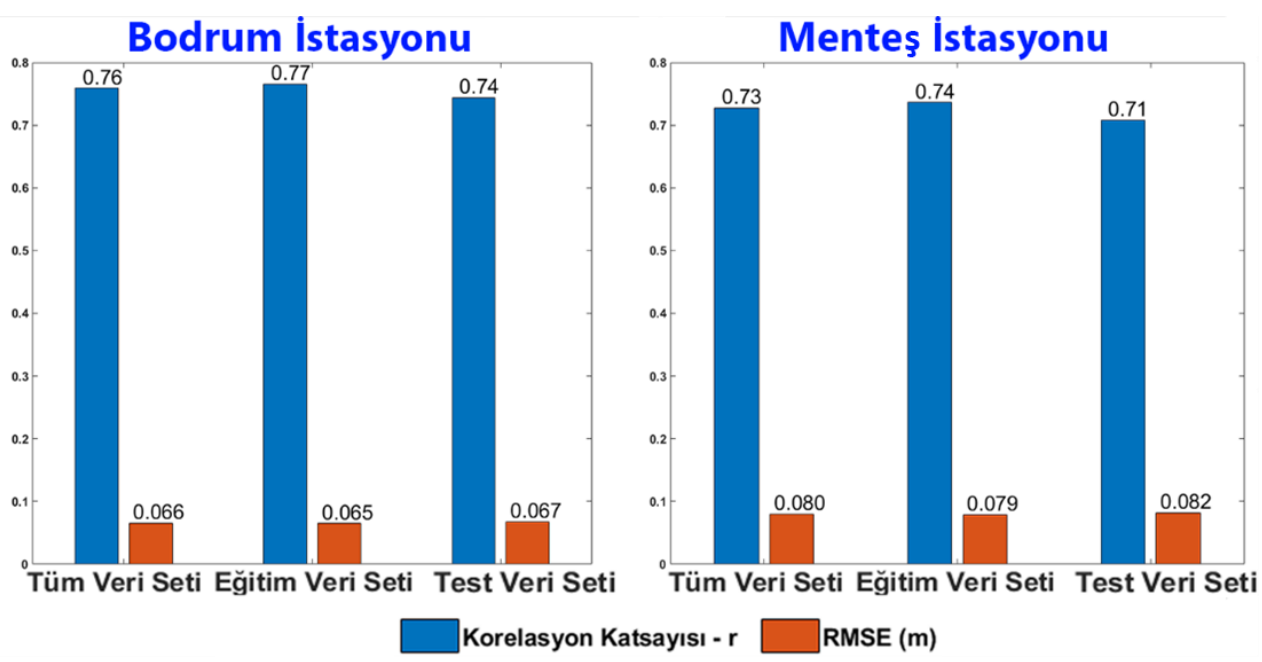

Şekil 11: DVR algoritması deniz seviyesi tahmin performansı

Şekil 10 ve Şekil 11'de görüldüğü gibi DVR algoritmasının deniz seviyesi tahmin performansı hem daha yüksek korelasyon hem de daha düşük RMSE metrikleri ile ÇDR algoritmasına göre daha iyidir.

\subsubsection{Rastgele Orman Regresyonu Algoritması Eğitim ve Test Performansı}

ROR algoritması ile deniz seviyesi tahmininin yüksek doğrulukta yapılabilmesi için karar ağacı ormanındaki ağaç sayısının doğru seçilmesi oldukça önemlidir. Bu çalışmada ROR algoritmasının içereceği ağaç sayısının belirlenmesi için RMSE ve $r$ doğruluk analizlerine dayanan bir yaklaşım kullanılmıştır. Algoritmadaki ağaç sayısının model doğruluğuna etkisi incelenerek kullanılacak ağaç sayısı belirlenmiştir. 10 ağaçtan başlayarak 200 ağaca kadar ROR algoritması ile deniz seviyesi tahminleri yapılmıştır. Bodrum istasyonu için yapılan tahminlere ilişkin model doğrulukları test veri seti için Şekil 12'deki gibidir.
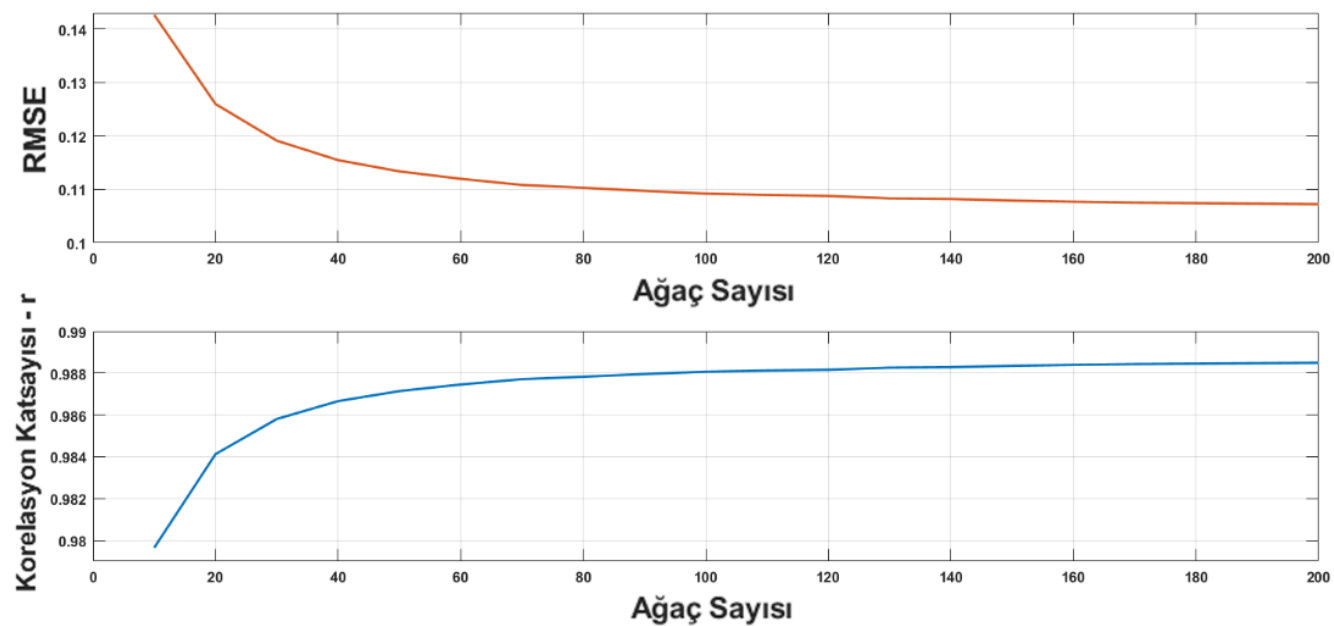

Şekil 12: ROR algoritmasında ağaç sayısının tahmin performansına etkisi

Şekil 12'de görüldüğü gibi ağaç sayısı arttıkça ROR modelinin tahmin performansı yükselmektedir. Ancak yaklaşık 100 ağaçtan sonra tahmin performansının hem korelasyon hem de RMSE metriği açısından fazla bir değişim göstermediği belirlenerek ROR algoritmasında kullanılacak ağaç sayısı 100 olarak seçilmiştir. ROR algoritmasının deniz seviyesine ilişkin tahminleri ve tahmin performansı sırasıyla Şekil 13 ve Şekil 14'te verilmiştir. 

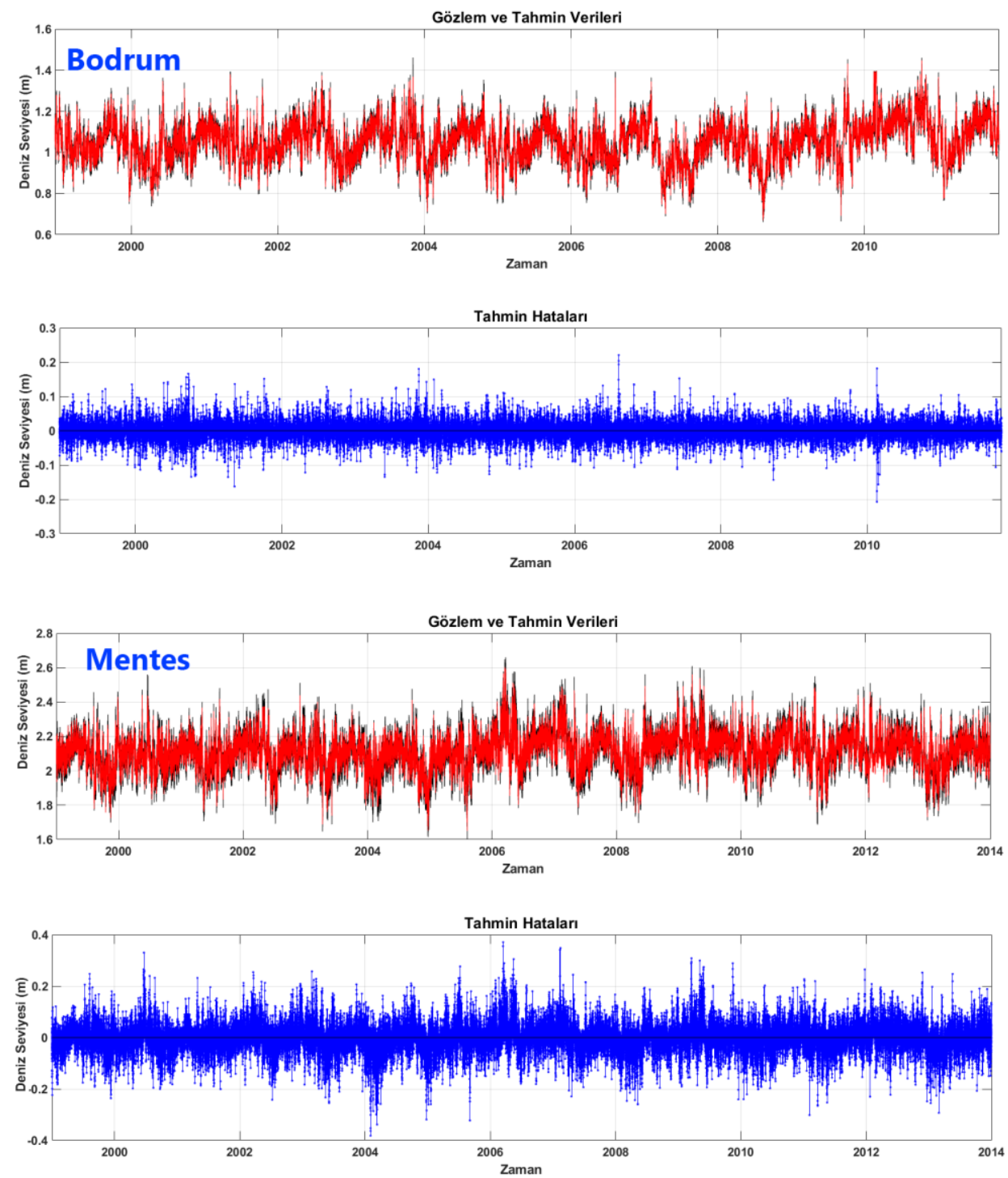

Şekil 13: ROR algoritması tahminleri (tüm veri seti için)

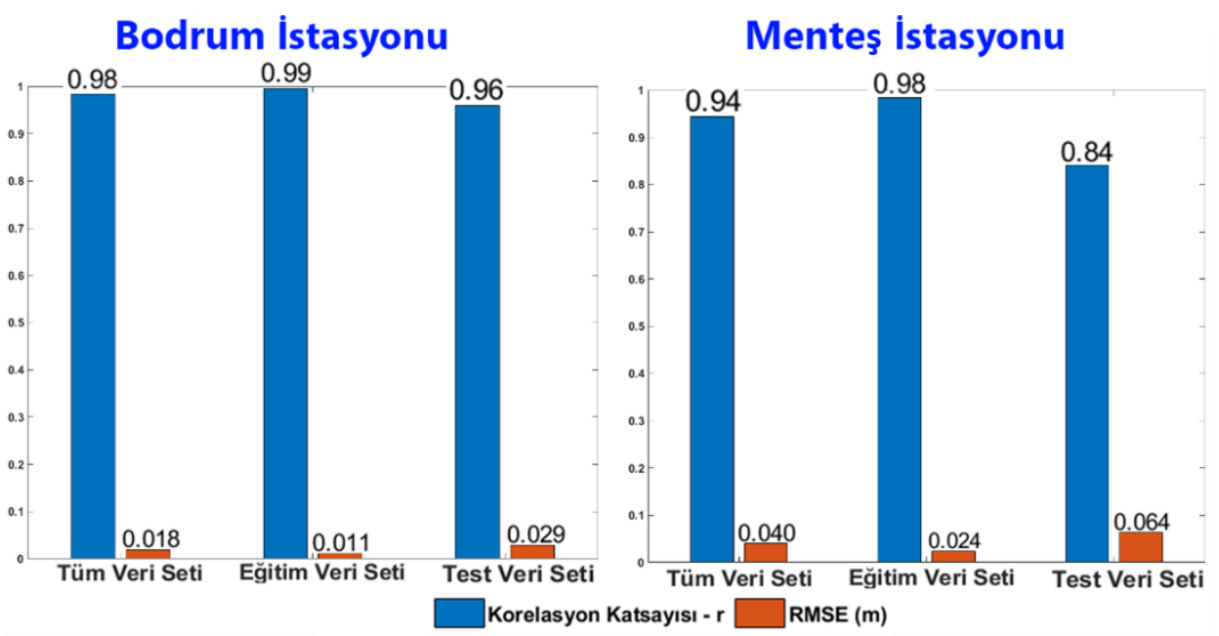

Şekil 14: ROR algoritması deniz seviyesi tahmin performansı

Şekil 13 ve Şekil 14'te görüldüğ̈̈ gibi ROR algoritmasının deniz seviyesi tahmin performansı hem eğitim hem de test veri seti için ÇDR ve DVR algoritmalarına kıyasla oldukça yüksektir. Bu yüksek doğruluktaki tahmin performansının, ROR algoritmasının karmaşık bağımlıık yapılarını kendi ağaç algoritma yapısı sayesinde modelleyebilmesinden kaynaklandığı 
değerlendirilmektedir.

\subsection{Makine Öğrenimi Algoritmalarının Karşılaştırılması}

Makine öğrenimi algoritmalarının eğitim verileri kullanılarak eğitilmesinin ardından test veri seti kullanılarak yapılan tahmin sonuçlarına ilişkin performans analizleri sonuçları Şekil 15 ‘de verilmiştir.

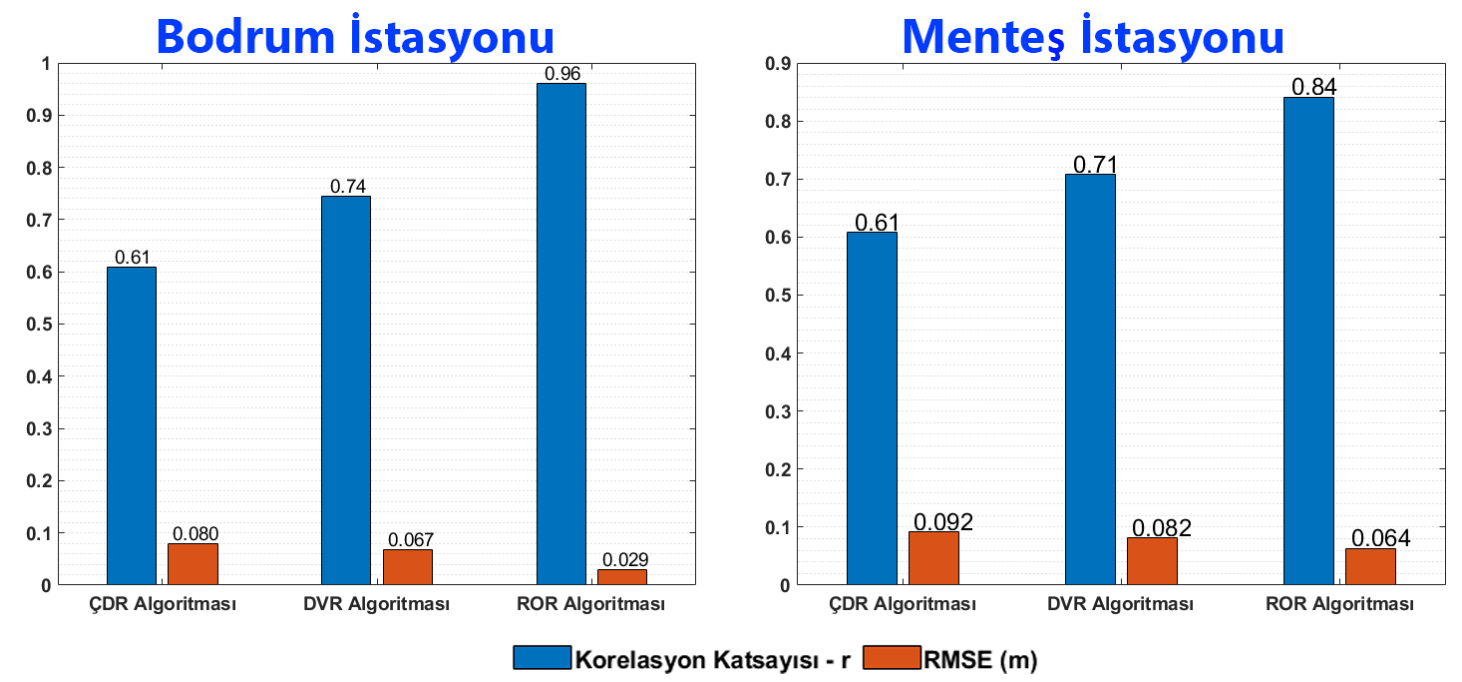

Şekil 15: Makine öğrenimi algoritmalarının karşılaştırılması

Her iki istasyonda da ÇDR ve DVR algoritmalarının test performansları ROR algoritmasına göre düşüktür. Ancak ROR algoritmasının performansı Bodrum istasyonunda daha yüksek olarak bulunmuştur. Bu durumun Menteş istasyonundaki eksik verilerin fazla olmasından ve daha fazla enterpolasyon verisi içermesinden kaynaklandığı değerlendirilmektedir. Eksik veriler her ne kadar enterpolasyon işlemleri ile tamamlansa da makine öğrenimi tahmin algoritmalarında model performansina etki etmektedirler.

\section{Sonuçlar}

Uzun dönemlere ait deniz seviyesi verileri ve meteorolojik veriler kullanılarak deniz seviyesinin yüksek doğrulukta kestirimi sonucunda kıyı yapılarının planlanması, küresel 1sınmanın etkilerinin tahmin edilmesi ve geleceğe yönelik etkin su politikalarının oluşturulması konularına katkı sağlayacağı değerlendirilmektedir. Bu çalışmada, Ege denizindeki iki mareograf istasyonundan elde edilen anlık deniz seviyelerinin tahmini için makine öğrenimi yöntemleri kullanılarak tahmin modelleri oluşturulmuş ve tahmin modellerinin performansları karşılaştırılmıştır. Makine öğrenimi algoritmalarının anlık deniz seviyesini tahmin etmek için kullanacağı öncül bilgiler istasyonlarda ölçülen meteorolojik veriler ve anlık deniz seviyesi zaman serilerinin doğrusal trend ve harmonik bileşenleridir. Bu kapsamda ÇDR, DVR ve ROR makine öğrenimi algoritmaları kullanılmıştır. Makine öğrenimi algoritmaları eğitim verileri ile eğitilmiş, test verileri kullanılarak deniz seviyesi tahmin performansları korelasyon katsayısı ve RMSE metrikleri ile değerlendirilmiştir. Yapılan analizler sonucunda mareograf istasyonlarında deniz seviyesi ROR algoritması kullanılarak \%96 ila \%84 korelasyon ve 29 ila 64 mm RMSE değerleri ile oldukça yüksek doğrulukta tahmin edilmiştir. En yüksek tahmin performansı ROR algoritması ile elde edilirken en düşük tahmin performansı ÇDR algoritması ile elde edilmiştir. Çalışma kapsamında elde edilen sonuçlar geçmişte yapılan çalışmalar ile karşılaştırıldığında, her ne kadar aynı veri setleri ve aynı öncül bilgiler kullanılmasa da okuyuculara ROR algoritmasının ve kullanılan öncül bilgilerin anlık deniz seviyesini belirlemedeki başarısı hakkında fikir vereceği düşünülmektedir. $\mathrm{Bu}$ nedenle geçmiş çalışmalar incelendiğinde, anlık deniz seviyeleri makine öğrenimi yöntemleri 
kullanılarak Imani vd. (2018) tarafından 34 mm, Imani vd. (2014a) tarafından 35 mm, Roshni vd. (2019) tarafindan 75 mm RMSE hassasiyetle belirlenirken, bu çalışmada anlık deniz seviyeleri Bodrum istasyonunda 29 mm, Menteş istasyonunda ise 64 mm RMSE ile belirlenmiştir.

Ayrıca elde edilen sonuçlar doğrusal tahmin modellerinin deniz seviyesini tahmin etmekte ne kadar yetersiz olduğunu göstermesi bakımından da oldukça önemlidir. Çünkü ÇDR algoritması doğrusal bir tahmin modeli olarak hem korelasyon hem de RMSE metrikleri bakımından doğrusal olmayan DVR ve ROR algoritmalarına göre düşük tahmin performansı göstermiştir. ROR algoritmasının ağaç algoritma yapısı sayesinde meteorolojik veriler, doğrusal trend ve harmonik bileşenler bağımsız değişkenleri kullanılarak deniz seviyesi yüksek doğrulukta kestirilmiştir. Anlık deniz seviyelerinin karmaşık bağımlılık yapılarının modellenmesinde ROR algoritmasının diğer algoritmalara göre daha başarılı olduğu belirlenmiştir.

\section{Teşekkür}

Çalışmada kullanılan TUDES verilerini https://tudes.harita.gov.tr/ linki üzerinden sağlayan Harita Genel Müdürlüğüne teşekkür ederiz.

\section{Yazar Katkısı}

Ahmet Yavuzdoğan: Literatür taraması, Veri işleme, Analiz ve yorumlama, Yazım. Emine Tanır Kayıkçı: Fikir, Tasarım, Denetleme, Makale değerlendirme.

\section{Çıkar Çatışması Beyanı}

Yazarlar, bu çalışmada bilinen ilgili herhangi bir finansal veya finansal olmayan çıkar çatışması olmadı̆̆ını beyan ederler.

\section{Kaynaklar}

Arns, A., Wahl, T., Wolff, C., Vafeidis, A. T., Haigh, I. D., Woodworth, P., Niehüser, S., \& Jensen, J. (2020). Non-linear interaction modulates global extreme sea levels, coastal flood exposure, and impacts. Nature communications, 11(1), 1-9.

Box, G. E., Jenkins, G. M., Reinsel, G. C., \& Ljung, G. M. (2015). Time series analysis: forecasting and control. John Wiley \& Sons.

Brundrit, G. B. (1995). Trends of southern African sea level: statistical analysis and interpretation. South African journal of marine science, 16(1), 9-17.

Chanklan, R., Kaoungku, N., Suksut, K., Kerdprasop, K., \& Kerdprasop, N. (2018). Runoff Prediction with a combined artificial neural network and support vector regression. International Journal of Machine Learning and Computing, 8(1).

Cortes, C., \& Vapnik, V. (1995). Support-vector networks. Machine learning, 20(3), 273-297.

Costa, C. G., Leite, J. R. B., Castro, B. M., Blumberg, A. F., Georgas, N., Dottori, M., \& Jordi, A. (2020). An operational forecasting system for physical processes in the Santos-Sao Vicente-Bertioga Estuarine System, Southeast Brazil. Ocean Dynamics, 70(2), $257-$ 271.

Drucker, H., Burges, C. J., Kaufman, L., Smola, A., \& Vapnik, V. (1997). Support vector regression machines. Advances in neural information processing systems, 9, 155-161.

Ertuğrul, Ö. F., \& Tağluk, M. E. (2017). Forecasting local mean sea level by generalized behavioral learning method. Arabian Journal for Science and Engineering, 42(8), 3289-3298.

Fu, Y., Zhou, X., Sun, W., \& Tang, Q. (2019). Hybrid model combining empirical mode decomposition, singular spectrum analysis, and least squares for satellite-derived sea-level anomaly prediction. International journal of remote sensing, 40(20), 7817-7829. 
Ghorbani, M. A., Khatibi, R., Aytek, A., Makarynskyy, O., \& Shiri, J. (2010). Sea water level forecasting using genetic programming and comparing the performance with artificial neural networks. Computers \& Geosciences, 36(5), 620-627.

Gülaçar, H. (2018). Nesnelerin İnterneti Platformları İçin Makine Öğrenmesi Tabanlı Bir Tahmin Modülü. (Yüksek Lisans Tezi), İstanbul Teknik Üniversitesi, Fen Bilimleri Enstitüsü, İstanbul, Türkiye.

Güven, A., \& Günal, M. (2008). Genetic programming approach for prediction of local scour downstream of hydraulic structures. Journal of Irrigation and Drainage Engineering, 134(2), 241-249.

Huang, M., Peng, G., Zhang, J., \& Zhang, S. (2006). Application of artificial neural networks to the prediction of dust storms in Northwest China. Global and Planetary change, 52(1-4), 216-224.

Imani, M., You, R. J., \& Chung-Yen, K. (2013). Accurate Forecasting of the satellite-derived seasonal Caspian sea level anomaly using polynomial interpolation and holt-winters exponential smoothing. Tao: terrestrial, atmospheric and oceanic sciences, $24(4), 521$.

Imani, M., You, R. J., \& Kuo, C. Y. (2014a). Forecasting Caspian Sea level changes using satellite altimetry data (June 1992-December 2013) based on evolutionary support vector regression algorithms and gene expression programming. Global and planetary change, 121, 53-63.

Imani, M., You, R. J., \& Kuo, C. Y. (2014b). Caspian Sea level prediction using satellite altimetry by artificial neural networks. International journal of environmental science and technology, 11(4), 1035-1042.

Imani, M., Kao, H. C., Lan, W. H., \& Kuo, C. Y. (2018). Daily sea level prediction at Chiayi coast, Taiwan using extreme learning machine and relevance vector machine. Global and planetary change, 161, 211-221.

Irvine, K. N., \& Eberhardt, A. J. (1992). Multiplicative, Seasonal Arima Models for Lake Erie And Lake Ontario Water Levels 1. JAWRA Journal of the American Water Resources Association, 28(2), 385-396.

Juva, K., Flögel, S., Karstensen, J., Linke, P., \& Dullo, W. C. (2020). Tidal dynamics control on cold-water coral growth: A high-resolution multivariable study on eastern Atlantic cold-water coral sites. Frontiers in Marine Science, 7(132).

Kim, K. J. (2003). Financial time series forecasting using support vector machines. Neurocomputing, 55(1-2), 307-319.

Kisi, O., Shiri, J., \& Nikoofar, B. (2012). Forecasting daily lake levels using artificial intelligence approaches. Computers \& Geosciences, 41, 169-180.

Makarynskyy, O., Makarynska, D., Kuhn, M., \& Featherstone, W. E. (2004). Predicting sea level variations with artificial neural networks at Hillarys Boat Harbour, Western Australia. Estuarine, Coastal and Shelf Science, 61(2), 351-360.

Meshkani, M. R., \& Meshkani, A. (1997). Stochastic modelling of the Caspian Sea level fluctuations. Theoretical and applied climatology, 58(3), 189-195.

More, A., \& Deo, M. C. (2003). Forecasting wind with neural networks. Marine structures, 16(1), 35-49.

Müller, K. R., Smola, A. J., Rätsch, G., Schölkopf, B., Kohlmorgen, J., \& Vapnik, V. (1997). Predicting time series with support vector machines. International Conference on Artificial Neural Networks (s. 999-1004). Berlin, Heidelberg: Springer.

Pawlowicz, R., Beardsley, B., \& Lentz, S. (2002). Classical tidal harmonic analysis including error estimates in MATLAB using T_TIDE. Computers \& Geosciences, 28(8), 929-937.

Pedregosa, F., Varoquaux, G., Gramfort, A., Michel, V., Thirion, B., Grisel, O., Blondel, M., Prettenhofer, P., Weiss, R., Dubourg, V., Vanderplas, J., Passos, A., Cournapeau, D., Brucher, M., Perot, M., \& Duchesnay, E. (2011). Scikit-learn: Machine learning in Python. the Journal of machine Learning research, 12, 2825-2830.

Pugh, D. T. (1996). Tides, surges and mean sea-level (reprinted with corrections). Chichester, UK: John Wiley \& Sons Ltd.

Rajasekaran, S., Gayathri, S., \& Lee, T. L. (2008). Support vector regression methodology for storm surge predictions. Ocean Engineering, 35(16), 1578-1587.

Roshni, T., Samui, P., \& Drisya, J. (2019). Operational use of machine learning models for sea-level modeling. Indian Journal of Geo Marine Sciences, 48(9), 1427-1434.

Sezen, E. (2006). Antalya-I (1935-1977) ve Antalya-II (1985-2005) Mareograf İstasyonlarında Deniz Seviyesi Değişimlerinin Araştırılması. (Yüksek Lisans Tezi), Afyon Kocatepe Üniversitesi, Afyonkarahisar, Türkiye.

Srivastava, P. K., Islam, T., Singh, S. K., Petropoulos, G. P., Gupta, M., \& Dai, Q. (2016). Forecasting Arabian Sea level rise using exponential smoothing state space models and ARIMA from TOPEX and Jason satellite radar altimeter data. Meteorological applications, 23(4), 633-639.

Şen, Z., Kadığlu, M., \& Batur, E. (2000). Stochastic modeling of the Van Lake monthly level fluctuations in Turkey. Theoretical and 
applied climatology, 65(1), 99-110.

Talebizadeh, M., \& Moridnejad, A. (2011). Uncertainty analysis for the forecast of lake level fluctuations using ensembles of ANN and ANFIS models. Expert Systems with applications, 38(4), 4126-4135.

Teferle, F. N. (2003). Strategies for Long Term Monitoring of Tide Gauges Using GPS. (Doktora Tezi). University of Nottingham, Nottingham, İngiltere.

Vaziri, M. (1997). Predicting Caspian Sea surface water level by ANN and ARIMA models. Journal of waterway, port, coastal, and ocean engineering, 123(4), 158-162.

Wu, C. L., \& Chau, K. W. (2010). Data-driven models for monthly streamflow time series prediction. Engineering Applications of Artificial Intelligence, 23(8), 1350-1367.

Yu, P. S., Chen, S. T., \& Chang, I. F. (2006). Support vector regression for real-time flood stage forecasting. Journal of Hydrology, 328(34), 704-716.

Yüksel, Y., \& Esin, Ç. (2016). Klyı Mühendisliği. İstanbul, Türkiye:.BETA Yayınevi.

Yüksel, Y., Öztürk, M., Şahin, C., Halat, O., Doğan, U., Yüksel, Z. T., \& Karova, C. (2018). Türkiye Denizlerinde Su Seviyesi Değişimi. 9. Klyı Mühendisliği Sempozyumu, Adana, Türkiye.

Zhao, J., Fan, Y., \& Mu, Y. (2019). Sea level prediction in the Yellow Sea from satellite altimetry with a combined least squares-neural network approach. Marine geodesy, 42(4), 344-366.

URL-1: https://tudes.harita.gov.tr/, (Erişim Tarihi : 06 Haziran 2019). 